\title{
Effect of Cyclic Mechanical Stimulation on the Expression of Osteogenesis Genes in Human Intraoral Mesenchymal Stromal and Progenitor Cells
}

\author{
Birgit Lohberger, ${ }^{1}$ Heike Kaltenegger, ${ }^{1}$ Nicole Stuendl, ${ }^{1}$ Michael Payer, ${ }^{2}$ \\ Beate Rinner, ${ }^{3}$ and Andreas Leithner ${ }^{1}$ \\ ${ }^{1}$ Department of Orthopaedic Surgery, Medical University of Graz, Auenbruggerplatz 5, 8036 Graz, Austria \\ ${ }^{2}$ Department of Oral Surgery and Radiology, School of Dental Medicine, Medical University of Graz, \\ Auenbruggerplatz 5, 8036 Graz, Austria \\ ${ }^{3}$ Center for Medical Research, Medical University of Graz, Auenbruggerplatz 5, 8036 Graz, Austria \\ Correspondence should be addressed to Birgit Lohberger; birgit.lohberger@medunigraz.at
}

Received 9 December 2013; Revised 3 March 2014; Accepted 4 March 2014; Published 7 April 2014

Academic Editor: Jiang Chang

Copyright (c) 2014 Birgit Lohberger et al. This is an open access article distributed under the Creative Commons Attribution License, which permits unrestricted use, distribution, and reproduction in any medium, provided the original work is properly cited.

\begin{abstract}
We evaluated the effects of mechanical stimulation on the osteogenic differentiation of human intraoral mesenchymal stem and progenitor cells (MSPCs) using the Flexcell FX5K Tension System that mediated cyclic tensile stretch on the cells. MSPCs were isolated from human mandibular retromolar bones and characterized using flow cytometry. The positive expression of CD73, CD90, and CD105 and negativity for CD14, CD19, CD34, CD45, and HLA-DR confirmed the MSPC phenotype. Mean MSPC doubling time was $30.4 \pm 2.1 \mathrm{hrs}$. The percentage of lactate dehydrogenase (LDH) release showed no significant difference between the mechanically stimulated groups and the unstimulated controls. Reverse transcription quantitative real-time PCR revealed that $10 \%$ continuous cyclic strain $(0.5 \mathrm{~Hz})$ for 7 and 14 days induced a significant increase in the mRNA expression of the osteogenesisspecific markers type-I collagen (Col1A1), osteonectin (SPARC), bone morphogenetic protein 2 (BMP2), osteopontin (SPP1), and osteocalcin (BGLAP) in osteogenic differentiated MSPCs. Furthermore, mechanically stimulated groups produced significantly higher amounts of calcium deposited into the cultures and alkaline phosphatase (ALP). These results will contribute to a better understanding of strain-induced bone remodelling and will form the basis for the correct choice of applied force in oral and maxillofacial surgery.
\end{abstract}

\section{Introduction}

Mesenchymal stem and progenitor cells (MSPCs) are promising candidates for cellular therapy in bone repair and regeneration of degenerative diseases due to their accessibility, expandability, and multipotent differentiation potential $[1-$ 6]. Bone marrow (BM) is regarded as the main source of MSPCs for experimental and clinical application [6], but due to the limited number of BM-MSPCs available for autogenous use, the implementation of alternative sources of MSPCs is particularly important. In a previous work, we identified intraoral tissues as potential sources of multipotent progenitor cells for tissue engineering approaches [7]. A major goal in implantology is the development of minimally invasive techniques that allow predictable alveolar crest reconstruction as well as reconstruction of critical size defects resulting from resorption, trauma, cancer, or metabolic disorders. Various techniques using mainly autogenous bone grafts alone or in combination with bone substitutes have, with varying degrees of success and with limitations mainly in regard to donor site morbidity, been introduced and established in daily practice [8-10].

It has been well documented that the bone remodelling process is initiated by the sensing of mechanical stimuli by osteocytes which in turn signal osteoblasts to form the bone matrix. By applying what is known about physiological 
conditions, it is reasonable to deduce that the same mechanical stimulation may play a role in the differentiation of MSPCs down an osteogenic pathway. Utilizing the principle of mechanically stimulating bone formation, uniaxial tensile strain was successfully used to induce bone regeneration via distraction osteogenesis [11-14]. Undifferentiated human MSPCs are highly sensitive to cyclic tensile strain which transcriptionally controls early osteochondrogenic response in vitro [15]. Strain alone can induce a significant increase in bone morphogenetic protein 2 (BMP2) mRNA levels in human BM-MSPCs without any addition of osteogenic supplements [16]. However, in vivo bone healing is much more effective when osteogenically differentiated cells are transplanted into the bone defect rather than undifferentiated MSPCs [17].

In this study, we used the FX5K Tension System to assess the effects of mechanical strain on in vitro differentiation to osteoblast-like cells, as well as the expression of osteogenesisrelated transcription factors. Undifferentiated and osteogenic differentiated human intraoral MSPCs were seeded into BioFlex plates and cultivated statically or dynamically over a 14-day period. Differentiation was assessed using reverse transcription quantitative real-time PCR for the runt-related transcription factor 2 (RUNX2), the early osteogenic markers alkaline phosphatase (ALPL), bone morphogenetic protein 2 (BMP2), type-I collagen (CollA1), and osteonectin (SPARC), and the osteogenic late stage markers osteocalcin (BGLAP) and osteopontin (SPP1).

The investigation of the effect of mechanical stimulation on human intraoral MSPCs provided insight into the mechanisms of bone regeneration, which play a major role in oral and maxillofacial surgery.

\section{Material and Methods}

2.1. Intraoral Tissue Harvest and Cell Culture. Explant MSPC cultures were established from intraoral tissue samples of posterior maxilla as well as from mandibular retromolar bone harvested during routine oral surgical interventions (wisdom tooth removal, augmentation procedures, and implantation). The study protocol was approved by the local ethics committee, and informed consent was obtained from each oral surgery patient. A total of ten patients, seven female and three male, aged between 15 and 47 were included in the study. Patients with metabolic bone diseases, local inflammatory processes, and impaired blood coagulation and pregnant women were excluded. The harvesting procedure was performed under sterile conditions with local anaesthesia (Ultracain Dental Forte, Maxilla; Sanofi-Aventis, Vienna, Austria) using a trephine burr $3.8 \mathrm{~mm}$ in diameter and $11 \mathrm{~mm}$ in length. The harvested bone samples were between 4 and $6 \mathrm{~mm}$ in length and showed cortical or cortical and cancellous structure. The obtained bone samples were rinsed extensively with phosphate-buffered saline (PBS; PAA Laboratory, Pasching, Austria) and cleaned with sharp instruments under the 10-fold magnification of a light microscope. After the cleaning procedure, the biopsies were transferred into $75 \mathrm{~cm}^{2}$ culture flasks (TPP, Trasadingen, Switzerland) with an appropriate volume of culture medium and incubated in a humidified atmosphere with $5 \% \mathrm{CO}_{2}$ at $37^{\circ} \mathrm{C}$ for cell isolation and expansion.

2.2. Cell Culture and Long-Term Expansion. MSPCs were cultured in $\alpha$-modified minimum essential medium ( $\alpha$ MEM; Sigma-Aldrich, Vienna, Austria) and supplemented with $10 \%$ pooled human platelet lysate (pHPL) [18] after the addition of $2 \mathrm{U} / \mathrm{mL}$ stabilisator-free heparin (Biochrom AG, Berlin, Germany), 2\% penicillin-streptomycin (GIBCO Invitrogen, Darmstadt, Germany), 0.5\% L-glutamine (GIBCO Invitrogen), $0.2 \%$ amphotericin B (PAA Laboratory), and 2.5\% HEPES buffer (Sigma-Aldrich, Vienna, Austria). Total MSPC cell number and doubling time were evaluated during cell expansion and MSPSs were then cultured with a reduced seeding density technique for three additional passages [19].

2.3. Flow Cytometry. A total of $1 \times 10^{5}$ MSPCs were resuspended in a final volume of $200 \mu \mathrm{L}$ PBS for flow cytometric analysis. The commercial monoclonal antibodies CD73 PE, CD90 APC, CD105 PE, CD45 APC-Cy7, CD34 APC, CD14 FITC, CD19 APC, and HLA-DR APC (BD Bioscience, San Jose, CA) were applied for characterization. The optimal amount of each antibody had previously been determined by titration and antibodies with nonoverlapping spectra were combined in two-colour staining panels. Background staining for antibodies was performed in negative cell lines and with matched fluorochrome-conjugated isotype controls. Flow cytometry analysis was performed on a FACS LSR II System (BD Bioscience), and data were acquired using FACSDiva software (BD Bioscience) and analysed with FCS Express software (De Novo Software, Los Angeles, CA). The day-to-day consistency of measurements was checked by Rainbow Beads (BD Bioscience). Viable cells were gated on forward scatter (FSC) and side scatter (SSC) in order to exclude debris and cell aggregates. MSPCs were defined by their phenotype and analysed on a logarithmic scale. Data from all donors were collected under identical parameters and analysed by collecting 10,000 events.

\subsection{Mechanical Stimulation. The Flexcell FX-5000 Tension} System (FX5K; Flexcell International Corp, Hillsborough, NC) was used to apply mechanical cyclic tensile stretch to the MSPCs. The Flexcell FX-5000 is a computer-based system that uses a vacuum to strain cells adhered to flexible silicon membranes (BioFlex plates; Flexcell International Corp) arranged in a format of six wells per plate with a total growth area of $9.62 \mathrm{~cm}^{2} /$ well and a membrane thickness of $0.05 \mathrm{~mm}$. The deformation of the flexible membrane of the plates also causes the attached cells to deform. Programming the magnitude, duration, and frequency of the negative pressure in the Flexcell apparatus creates desired strain profiles. MSPCs were seeded onto the collagen type-I-coated BioFlex plates at a density of $5 \times 10^{4}$ cells/well. When cultures reached approximately $70 \%$ to $80 \%$ confluence, undifferentiated (EX) and osteogenic differentiated (OG) MSPCs were subjected to continuous mechanical stimulation with a uniaxial sinusoidal waveform with $10 \%$ elongation and a frequency of $0.5 \mathrm{~Hz}$ for 


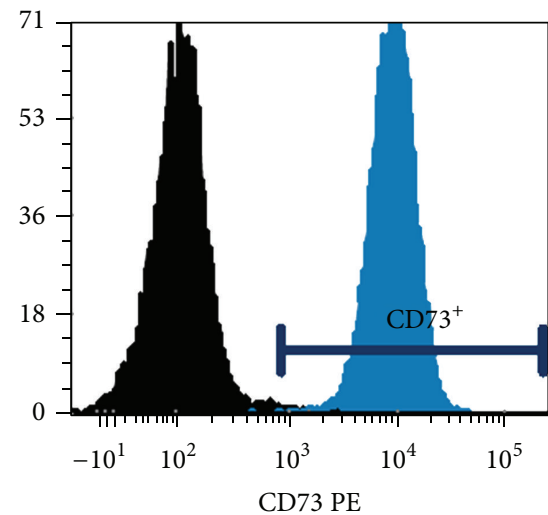

(a)

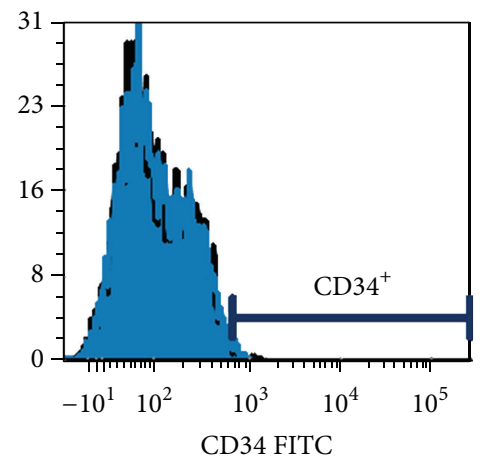

(d)

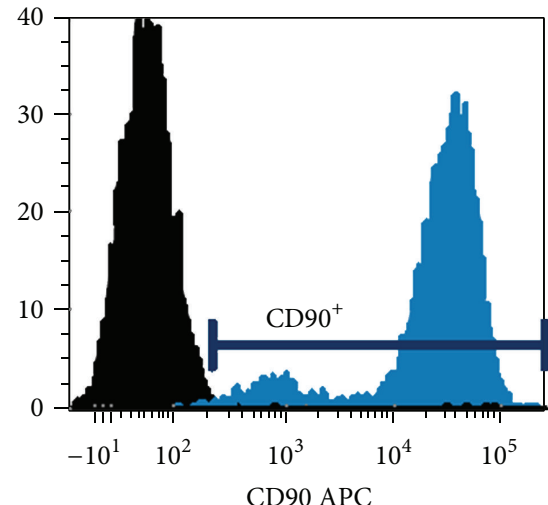

(b)

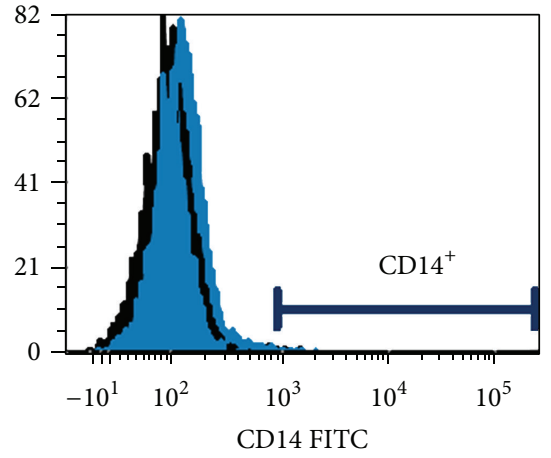

(e)

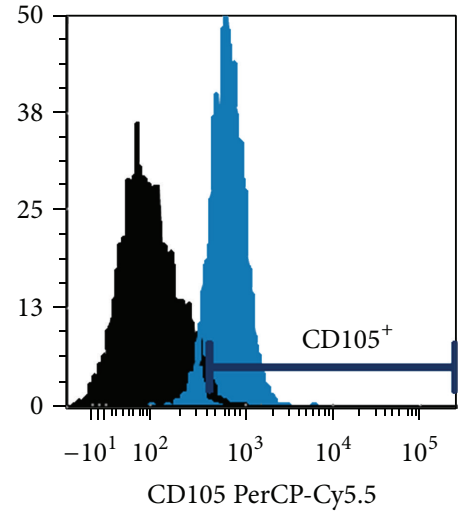

(c)

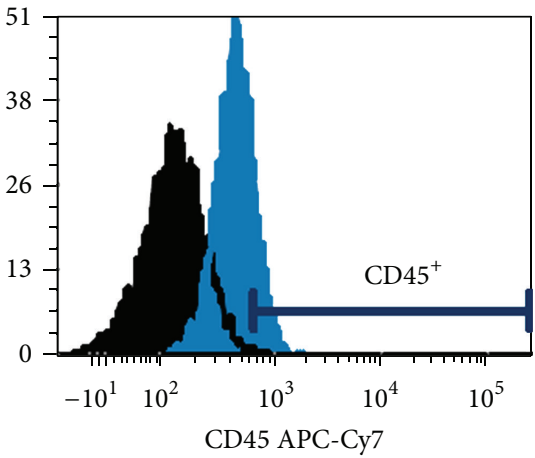

(f)

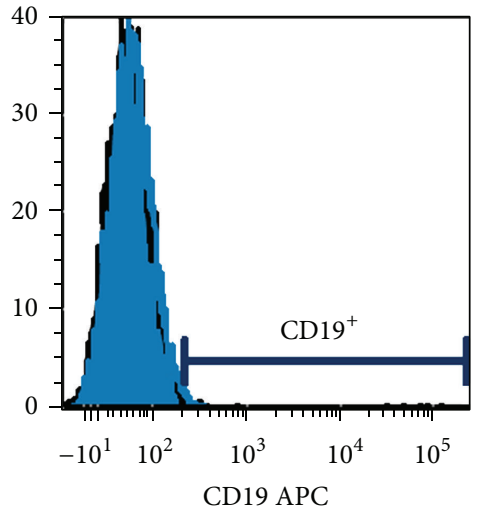

(g)

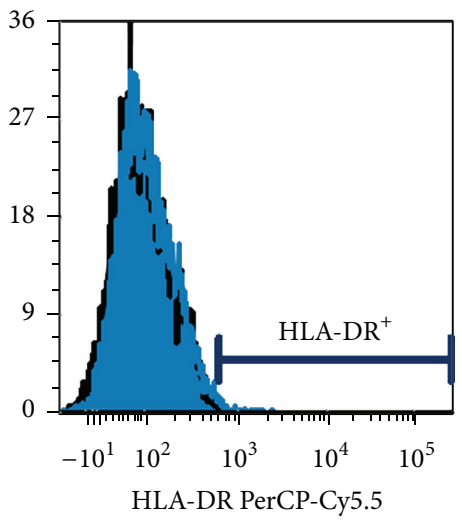

(h)

Figure 1: Multicolour flow cytometric immunophenotypic analysis with monoclonal antibodies. Intraoral MSPCs at passages 3-7 were labelled with specific fluorochrome-conjugated monoclonal antibodies against the indicated surface antigens and analysed by flow cytometry. Analysed MSPCs demonstrated the same immunophenotype, with expression of (a) CD73, (b) CD90, and (c) CD105 but no expression of (d) CD14, (e) CD19, (f) CD34, (g) CD45, and (h) HLA-DR. A representative example of ten experiments is shown. PE: phycoerythrin; APC: allophycocyanin; PerCP: peridium-chlorophyll protein complex; FITC: fluorescein isothiocyanate.

7 and 14 days. Each cycle consisted of $10 \mathrm{~s}$ strain and $30 \mathrm{~s}$ relaxation (Figure 2(a)). Control cultures were grown under the same conditions but without the strain protocol. Control cultures were grown under the same conditions but without the strain protocol.

2.5. Osteogenic Differentiation. Intraoral MSPCs used for osteogenic differentiation were derived from the third to sixth passage. MSPCs were seeded at a density of $10^{4}$ cells $/ \mathrm{cm}^{2}$ in expansion medium containing Dulbecco's Modified Eagle's Medium (DMEM-F12; GIBCO Invitrogen), 10\% FBS (Lonza, Braine-l'Alleud, Belgium), 1\% penicillinstreptomycin, $1 \%$ L-glutamine, and $0.1 \%$ amphotericin B. Osteogenic differentiation was induced over two weeks by shifting the cells to an osteoinductive medium (OG) composed of the expansion medium supplemented with 


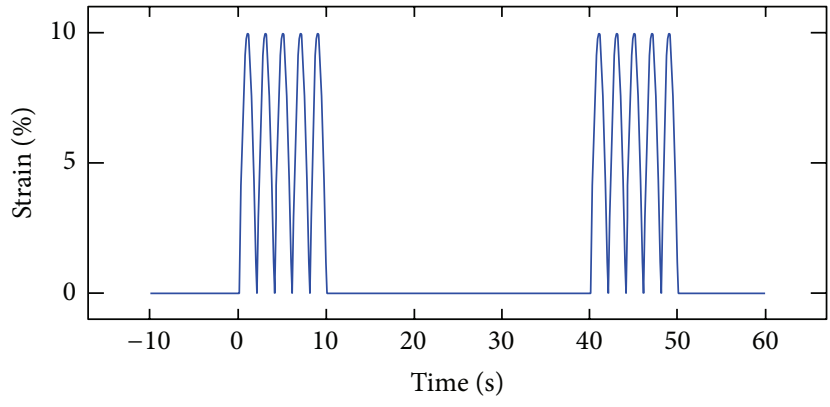

(a)

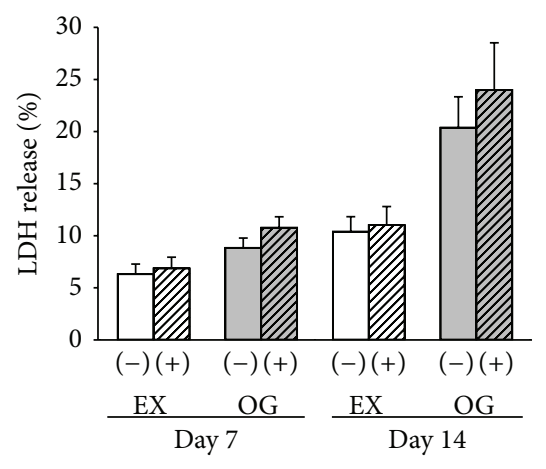

(b)

FIGURE 2: Straining profile and effects of mechanical stimulation on the release of lactate dehydrogenase (LDH) from human intraoral MSPCs. (a) Profile of a uniaxial sinusoidal waveform with $10 \%$ elongation and a frequency of $0.5 \mathrm{~Hz}$, whereby each cycle consists of $10 \mathrm{~s}$ strain and 30 s relaxation. (b) The percentage of LDH released into the culture media was measured after 7 and 14 days of culture. Each bar represents the mean \pm SD of independent experiments performed in triplicate $(n=8) ;{ }^{*} P<0.05$.

$100 \mathrm{nM}$ dexamethasone, $0.1 \mathrm{mM}$ ascorbic-acid-2-phosphate, and $10 \mathrm{mM} \beta$-glycerophosphate (all from Sigma-Aldrich). Alkaline phosphatase (ALP) enzyme activity was photometrically determined at day 14 in triplicate with a p-nitrophenyl phosphate liquid substrate system (Sigma-Aldrich) at $405 \mathrm{~nm}$ on a microplate reader (BioRad, Vienna, Austria) [20]. For the visualization and quantification of calcium phosphate deposits, Alizarin Red S (ARS) staining was used at days 7 and 14. Cells were fixed with 10\% formaldehyde (Merck, Spittal/Drau, Austria) and incubated with a 1\% ARS staining solution. Quantitation of ARS staining was performed by elution of the fixed cells with $10 \%$ cetylpyridinium chloride (Sigma-Aldrich) measuring absorbance at $570 \mathrm{~nm}$ on a microplate reader [21].

2.6. Lactate Dehydrogenase Assay. Lactate dehydrogenase $(\mathrm{LDH})$ activity was measured using the CytoTox-ONE Homogeneous Membrane Integrity Assay (Promega, Mannheim, Germany). The amount of fluorescence produced is proportional to the number of lysed cells. After 7 and 14 days of mechanical stimulation, cell culture supernatants were collected and analysed to examine the state of cellular damage. In short, $50 \mu \mathrm{L}$ of supernatant and $50 \mu \mathrm{L}$ of working solution were mixed in white 96-well microtiter plates and incubated in the dark at room temperature for 30 minutes. The reaction was terminated by the addition of $50 \mu \mathrm{L}$ stop solution and fluorescence was measured at 560/590 nm (Fluostar; BMC Labtech, Ortenberg, Germany).

2.7. Reverse Transcription Quantitative Real-Time PCR (RT$q P C R)$. RT-qPCR was performed in order to determine the relative expression of the early osteogenic markers ALPL, BMP2, CollA1, RUNX2, and SPARC and the osteogenic late stage markers BGLAP and SPP1. Total RNA was isolated from osteogenic differentiated and undifferentiated control cells with RNeasy Mini Kit (Qiagen, Hilden, Germany) according to the manufacturer's recommended protocol. RNA quality was analysed using the Agilent RNA 6000 Nano Kit and the
Bioanalyzer 2100 (Agilent Technologies, Santa Clara, CA). All RIN values were between 9.2 and 10.0. DNA was digested with $1 \mathrm{U}$ DNase (Fermentas, St. Leon-Rot, Germany) per $\mu \mathrm{g}$ RNA. One $\mu \mathrm{g}$ RNA was reverse transcribed using RevertAid cDNA Synthesis Kit (Fermentas). RT-qPCR reactions were performed in triplicate using the Platinum SYBR Green Super Mix with ROX (Invitrogen) on AB7900HT (Applied Biosystems, Invitrogen). The reference genes glyceraldehyde 3 -phosphate dehydrogenase (GAPDH), $\beta$-actin (ACTB), and hypoxanthine phosphoribosyltransferase (hprt-n) were used for normalization and in order to show their stable expression in different tissues [22]. The following primers were used for RT-qPCR: QuantiTect primer assays (Qiagen) for ALPL (ID QT00012957), BMP2 (ID QT00012544), Col1A1 (ID QT00037793), RUNX2 (ID QT00020517), SPARC (ID QT00018620), BGLAP (ID QT00232771), and SPP1 (ID QT01008798). The expression level $\left(C_{T}\right)$ of the target gene was normalized to the reference genes (GAPDH, ACTB, and hprtn) $\left(\Delta C_{t}\right)$ and then the $\Delta C_{t}$ of the test sample was normalized to the $\Delta C_{t}$ of the controls $\left(\Delta \Delta C_{t}\right)$. Finally, the expression ratio was calculated with the $2^{-\Delta \Delta C_{t}}$ method $\left({ }^{*} P<0.05\right)[23]$.

2.8. Statistical Analysis. All values are expressed as mean \pm standard deviation (SD). The exact Wilcoxon test was used to evaluate the differences between groups. The exact Friedman test (more than two time points) and the exact paired Wilcoxon test ( 2 time points) were applied to test for changes between time points. Two-sided $P$ values below 0.05 were considered statistically significant. $P$ values were not adjusted for multiple comparisons. Graphic data were prepared with SigmaPlot (Systat Software Inc., San Jose, CA).

\section{Results}

3.1. Expansion of Human Intraoral MSCPs. Bone explants were successfully harvested during routine oral surgery interventions in all patients $(n=10)$. Evaluation of postoperative pain and patient satisfaction revealed no difference compared 
TABLE 1: Expression of intraoral MSPC surface proteins analysed by flow cytometry.

\begin{tabular}{lc}
\hline Cluster of differentiation $(\mathrm{CD})$ & Positivity (\%) \\
\hline CD73 PE & $99.8 \pm 0.1$ \\
CD90 APC & $99.9 \pm 0.1$ \\
CD105 PerCP-Cy5.5 & $69.1 \pm 9.8$ \\
CD14 FITC & $0.2 \pm 0.2$ \\
CD19 APC & $0.6 \pm 0.1$ \\
CD34 FITC & $0.4 \pm 0.3$ \\
CD45 APC-Cy7 & $23.9 \pm 7.8$ \\
HLA-DR PerCP-Cy5.5 & $0.5 \pm 0.3$ \\
\hline
\end{tabular}

Expression of intraoral MSPC surface proteins analysed by flow cytometry. Mean values of the percentage of positive cells \pm SD to the total number of analysed cells are shown $(n=10)$. PE: phycoerythrin; APC: allophycocyanin; PerCP: peridium-chlorophyll protein complex; FITC: fluorescein isothiocyanate.

to the control group. Cells exhibiting morphologic characteristics of human BM-stromal cells (mononuclear, fibroblastlike, spindle-shaped, and plastic-adherent) were isolated from all samples within 4 to 8 days, independent of donor gender, age, or macroscopic bone explant structure. Confluence was reached after 13 to 15 days. To expand maxillary cells and analyse the cell doubling time, cells were trypsinised and cultivated with a reduced seeding density technique for three additional passages. The doubling time of each culture of passage three was calculated with a two time-point calculation formulas $T d=\left(t_{2}-t_{1}\right) * \log (2) / \log \left(q_{2} / q_{1}\right)\left(t_{1}, t_{2}=\right.$ time points; $q_{1}, q_{2}=$ growing quantities. The mean doubling time of the MSPCs was $30.4 \pm 2.1 \mathrm{hrs}$. The mean total number of cells after three passages was $1.2 \pm 0.2 \times 10^{7}$.

3.2. Characterization of Human Intraoral MSCPs by Flow Cytometry. Viable cells were gated on the forward/side scatter, and aggregates were excluded with the FSC/W and FSC/A. The positive expression of CD73, CD90, and CD105, low level of CD45, and negativity for CD14, CD19, CD34, and HLA-DR confirmed the phenotype of intraoral MSPCs (Figure 1). Intraoral MSPCs from all patients demonstrated the same immunophenotype. Flow cytometry data are shown in Figure 1 and Table 1.

\subsection{Intraoral MSPC Morphology and Cellular Activity during} Mechanical Stimulation. The strain profile used in the present study was based on the timing and theorized intensity profiles of common repetitive motion strains that are often the result of masticatory movements (Figure 2(a)). No morphological differences were observed between the mechanically stimulated groups and unstimulated groups. However, the uniform alignment of cells was observed for the mechanically stimulated groups. The percentage of LDH release showed no significant differences between the mechanically stimulated groups $(\mathrm{EX}(+)$ and $\mathrm{OG}(+))$ and unstimulated groups (EX(-) and $\mathrm{OG}(-))$ (Figure 2(b)).
3.4. Expression of Osteogenesis-Specific Markers Affected by Mechanical Stimulation. To determine the influence of $10 \%$ cyclin strain on osteogenesis, undifferentiated (EX) and osteogenic differentiated (OG) human intraoral MSPCs were mechanically stimulated with the Flexcell FX5K Tension System for 14 days. Relative mRNA expression levels of the runtrelated transcription factor 2 (RUNX2), the early osteogenic markers type-I collagen (CollA1), osteonectin (SPARC), bone morphogenetic protein 2 (BMP2), and alkaline phosphatase (ALPL), and the osteogenic late stage markers osteopontin (SPP1) and osteocalcin (BGLAP) were analysed by RT-qPCR after 7 and 14 days of mechanical stimulation. The undifferentiated and mechanically unstimulated group (EX(-)) served as the reference value (ratio $=1$ ). RUNX2 mRNA levels showed a clear, but not statistically significant, increase after 14 days of mechanical stimulation. Following 7 and 14 days of cyclic strain, the expression of CollA1 increased significantly in the mechanically stimulated OG cells at both time points. The expression of the late stage marker SPP1 increased significantly during osteoinduction in $\mathrm{OG}(+)$ cells. However, no significant differences between the four groups were indicated in the mRNA expression of BGLAP. The most significant increase was observed by the BMP2 expression. SPARC expression was increased in the osteogenic differentiated mechanically unstimulated group OG( $(-)$ at day 7 and in the $\mathrm{OG}(+)$ cells at day 14 when compared to the $\mathrm{EX}(-)$ controls. After both time points, a significant increase in ALDL expression was observed in the $\mathrm{OG}(-)$ and $\mathrm{OG}(+)$ cells. All values are listed in Table 2 .

3.5. Mechanical Stimulation Enhanced the Expression of Osteogenesis-Specific Markers. To investigate the influence of the mechanical stimulation on both undifferentiated and osteogenic differentiated intraoral MSPCs, RT-qPCR values were subjected to a further evaluation. Mechanically stimulated cells were compared to the respective unstimulated control cells. Whereas the undifferentiated (EX) intraoral MSPCs showed no change in the osteogenesis-specific marker expression, mechanical stimulation increased the expression of CollA1, SPP1, BGLAP, BMP2, and SPARC significantly in the osteogenic differentiated (OG) cells. Specifically, whereas no significant differences between cyclic strain and static condition could be observed by RUNX2 (Figure 3(a)), CollA1 mRNA levels increased to $1.79 \pm 0.73$ $(P=0.029)$ after 7 days and to $2.09 \pm 0.71(P=0.026)$ after 14 days of mechanical stimulation (Figure 3(b)). SPP1 increased significantly in the mechanically stimulated OG cells to $2.88 \pm$ $0.34(P=0.0002)$ at day 7 and $5.25 \pm 1.37(P=0.033)$ at day 14 (Figure 3(c)). BGLAP expression considerably to $1.72 \pm 0.52(P=0.037)$ in $\mathrm{OG}(+)$ cells exposed to 14 days of mechanical strain (Figure 3(d)). The most significant increase was observed in the BMP2 expression after 7 days (5.66 \pm 3.98; $P=0.021)$ and 14 days $(6.60 \pm 4.82 ; P=0.048)$ of mechanical stimulation (Figure 3(e)). SPARC expression increased significantly to $1.77 \pm 0.46(P=0.020)$ in $\mathrm{OG}(+)$ cells exposed to 14 days of mechanical strain (Figure 3(f))

In addition, ARS staining of calcium deposits and absorbance measurements of ARS-stained intraoral MSPCs 


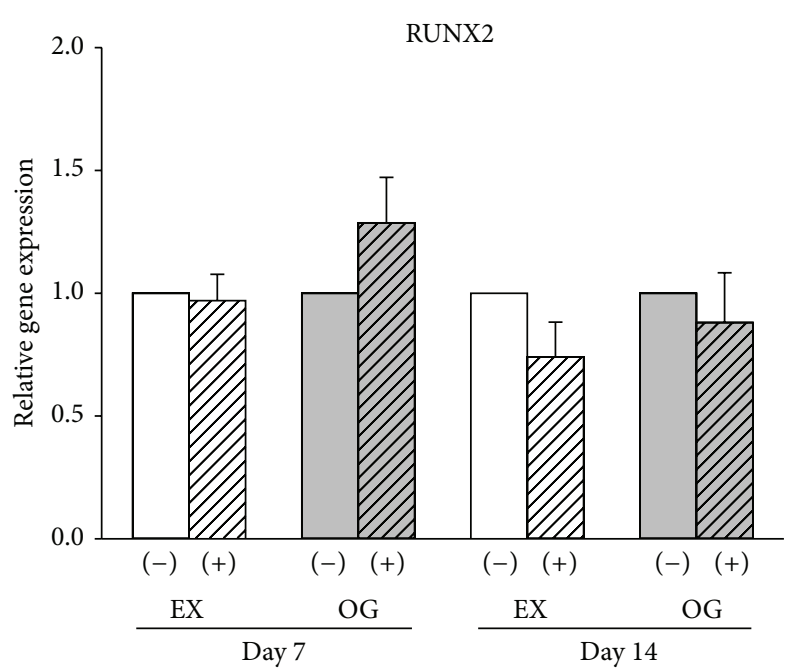

(a)

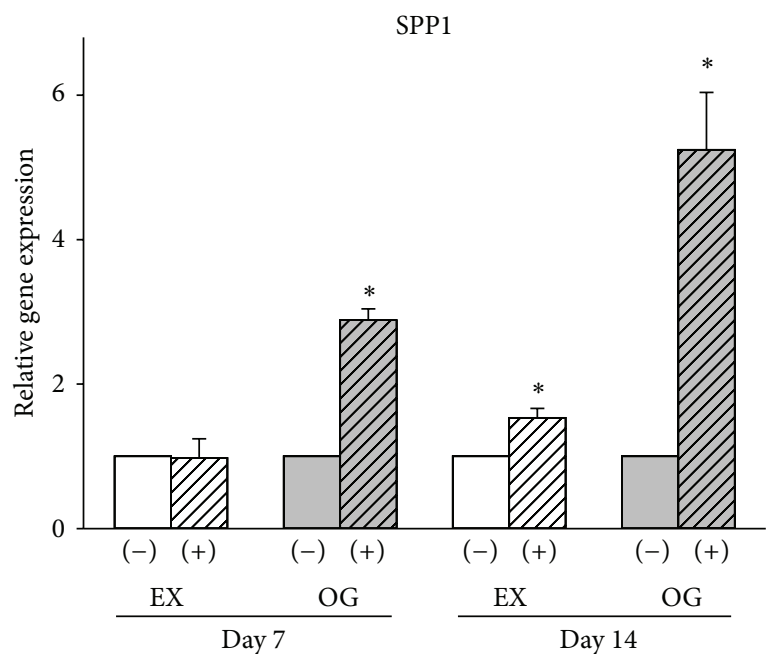

(c)

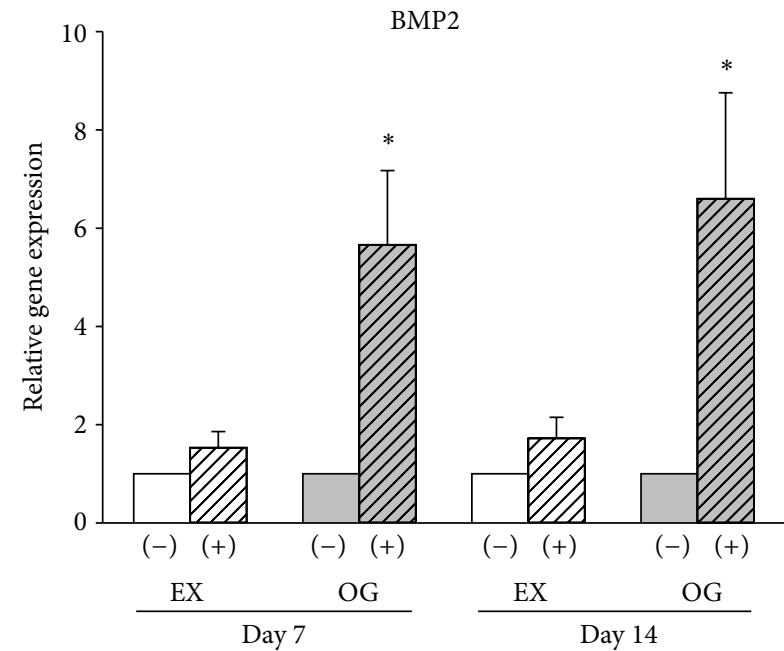

(e)

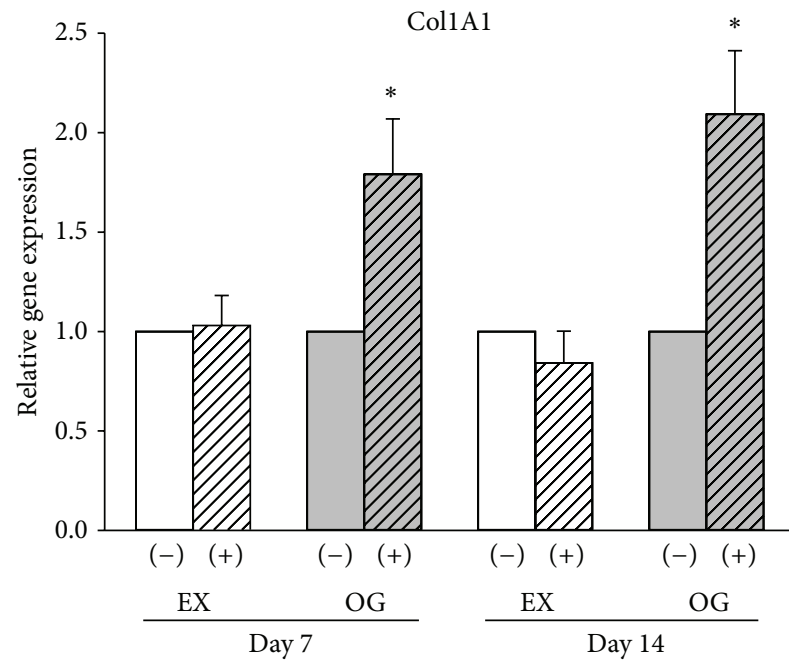

(b)

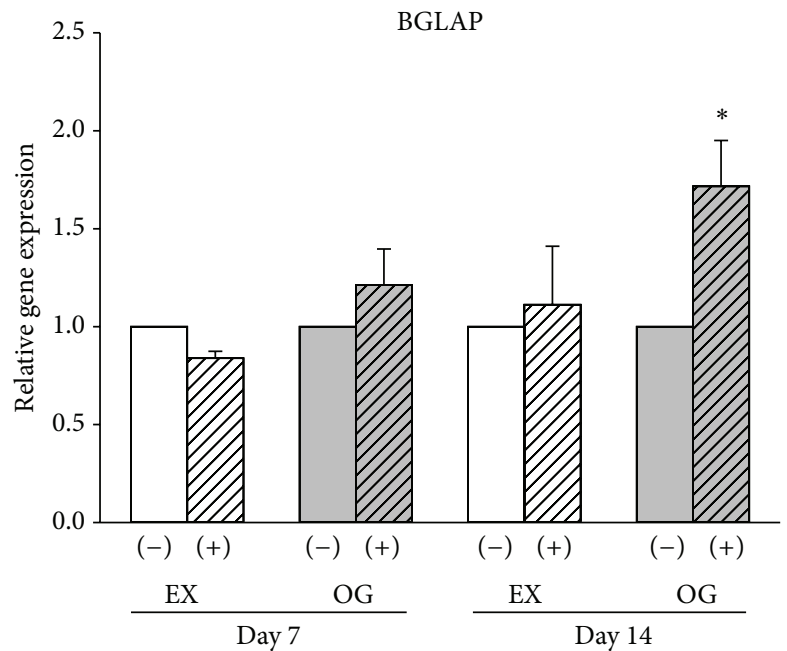

(d)

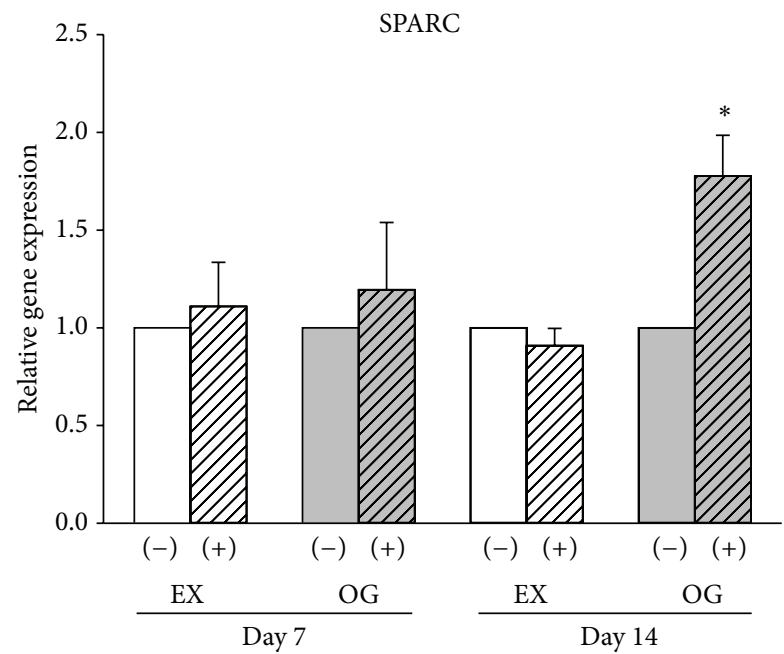

(f)

FIGURE 3: Regulation of osteogenesis-specific markers under the influence of mechanical stimulation. mRNA levels of (a) RUNX2, (b) Col1A1, (c) SPP1, (d) BGLAP, (e) BMP2, and (f) SPARC were normalized to their respective mechanically unstimulated control groups. $\mathrm{EX}(-)$ represents the undifferentiated mechanically unstimulated group, $\mathrm{EX}(+)$ the undifferentiated mechanically stimulated group, OG(-) the osteogenic differentiated mechanically unstimulated group, and OG(+) the osteogenic differentiated mechanically stimulated group. The values are mean $\pm \mathrm{SD}$ of independent experiments performed in triplicate $(n=7) ;{ }^{*} P<0.05$. 
TABLE 2: Expression of the osteogenesis-specific markers affected by mechanical stimulation for 7 and 14 days.

\begin{tabular}{|c|c|c|c|c|c|c|c|c|}
\hline & \multicolumn{4}{|c|}{ Day 7} & \multicolumn{4}{|c|}{ Day 14} \\
\hline & $\mathrm{EX}(-)$ & $\mathrm{EX}(+)$ & $\mathrm{OG}(-)$ & $\mathrm{OG}(+)$ & $\mathrm{EX}(-)$ & $\mathrm{EX}(+)$ & OG(-) & $\mathrm{OG}(+)$ \\
\hline RUNX2 & 1 & $1.01 \pm 0.3$ & $0.98 \pm 0.3$ & $1.40 \pm 0.5$ & 1 & $0.75 \pm 0.3$ & $2.48 \pm 0.6$ & $3.13 \pm 1.1$ \\
\hline Col1A1 & 1 & $1.16 \pm 0.3$ & $1.70 \pm 0.8$ & $\begin{array}{l}2.92 \pm 1.1 \\
P=0.0039\end{array}$ & 1 & $0.68 \pm 0.4$ & $0.94 \pm 0.4$ & $\begin{array}{r}2.02 \pm 0.9 \\
P=0.049\end{array}$ \\
\hline SPP1 & 1 & $0.95 \pm 0.3$ & $1.11 \pm 0.4$ & $\begin{array}{c}1.91 \pm 0.5 \\
P=0.040\end{array}$ & 1 & $1.44 \pm 0.7$ & $1.48 \pm 0.2$ & $\begin{array}{c}2.92 \pm 0.8 \\
P=0.038\end{array}$ \\
\hline BGLAP & 1 & $0.85 \pm 0.1$ & $0.78 \pm 0.4$ & $0.84 \pm 0.5$ & 1 & $0.67 \pm 0.2$ & $0.91 \pm 0.5$ & $1.08 \pm 0.2$ \\
\hline BMP2 & 1 & $1.53 \pm 0.8$ & $2.17 \pm 1.3$ & $\begin{array}{c}5.54 \pm 3.2 \\
P=0.036\end{array}$ & 1 & $2.06 \pm 1.0$ & $3.84 \pm 1.8$ & $\begin{array}{r}6.48 \pm 3.5 \\
P=0.013\end{array}$ \\
\hline SPARC & 1 & $0.93 \pm 0.2$ & $\begin{array}{r}1.47 \pm 0.4 \\
P=0.035\end{array}$ & $1.60 \pm 0.9$ & 1 & $0.88 \pm 0.3$ & $0.95 \pm 0.4$ & $\begin{array}{c}2.13 \pm 0.8 \\
P=0.044\end{array}$ \\
\hline ALPL & 1 & $0.86 \pm 0.4$ & $\begin{array}{c}5.35 \pm 1.9 \\
P=0.042\end{array}$ & $\begin{array}{l}4.05 \pm 1.8 \\
P=0.046\end{array}$ & 1 & $0.78 \pm 0.5$ & $\begin{array}{c}3.55 \pm 1.6 \\
P=0.023\end{array}$ & $\begin{array}{c}3.62 \pm 1.8 \\
P=0.042\end{array}$ \\
\hline
\end{tabular}

mRNA levels of RUNX2, Col1A1, SPP1, and BGLAP. BMP2 and ALPL were normalized to the undifferentiated mechanically unstimulated control group EX(-) of each day $($ ratio $=1)$. EX $(+)$ represents the undifferentiated mechanically stimulated group, OG $(-)$ the osteogenic differentiated mechanically unstimulated group, and $\mathrm{OG}(+)$ the osteogenic differentiated mechanically stimulated group. The values are mean $\pm \mathrm{SD}$ of independent experiments performed in triplicate $(n=7) ;{ }^{*} P<0.05$.

TABLE 3: Quantitation of ARS staining of calcium deposits and ALP enzyme.

\begin{tabular}{|c|c|c|c|c|}
\hline & $\mathrm{EX}(-)$ & $\mathrm{EX}(+)$ & $\mathrm{OG}(-)$ & $\mathrm{OG}(+)$ \\
\hline ARS day 7 & $0.12 \pm 0.01$ & $0.11 \pm 0.01$ & $0.16 \pm 0.02$ & $0.20 \pm 0.05$ \\
\hline EX versus OG & & & $P=2.15 E-05$ & $P=0.002$ \\
\hline$(-)$ versus $(+)$ & & & & $P=0.037$ \\
\hline ARS day 14 & $0.24 \pm 0.06$ & $0.20 \pm 0.02$ & $0.31 \pm 0.06$ & $0.92 \pm 0.19$ \\
\hline EX versus OG & & & $P=0.007$ & $P=6.56 E-10$ \\
\hline$(-)$ versus $(+)$ & & & & $P=2.02 E-9$ \\
\hline ALP day 14 & $0.09 \pm 0.01$ & $0.09 \pm 0.01$ & $0.12 \pm 0.02$ & $0.18 \pm 0.04$ \\
\hline EX versus OG & & & & $P=0.0004$ \\
\hline$(-)$ versus $(+)$ & & & & $P=0.005$ \\
\hline
\end{tabular}

The ARS staining of calcium deposits and measurements of an OD of $570 \mathrm{~nm}$ after cetylpyridinium chloride elution were performed at days 7 and 14 . Quantitation of calcium deposits revealed a highly significant increase of an OD of $570 \mathrm{~nm}$ values in osteogenic differentiated cells (OG) compared to the corresponding undifferentiated controls (EX). Mechanical stimulation revealed a significant increase in calcium deposits in the OG(-) cells compared to the $\mathrm{OG}(+)$ cells. Quantitation of ALP enzyme at day 14 revealed a significant increase in osteogenic differentiated cells (OG) compared to the corresponding undifferentiated controls (EX). The values are mean \pm SD of independent experiments performed in triplicate $(n=12) ;{ }^{*} P<0.05$.

eluted with cetylpyridinium chloride at an optical density (OD) of $570 \mathrm{~nm}$ were performed at days 7 and 14. Representative pictures of unstained $(\mathrm{EX}(-)$ and $\operatorname{EX}(+))$ and osteogenic differentiated $(\mathrm{OG}(-)$ and $\mathrm{OG}(+))$ MSPCs are shown in Figure 4(a). Values measured at an OD of $570 \mathrm{~nm}$ increased significantly over time in osteogenic lineage cells when compared to undifferentiated controls. Corresponding to the RT-qPCR data, mechanical stimulation revealed a significant increase of quantifiable calcium deposits in the $\mathrm{OG}(-)$ cells compared to the OG(+) cells (Figures 4(b) and 4(c)). ALP activity was measured over the absorbance of p-nitrophenol phosphate, a chromogenic product with absorbance at $405 \mathrm{~nm}$, in supernatant after 14 days. Again, cyclic strain enhanced the activity of ALP in the OG(+) cells compared to the OG( -$)$ cells $(P=0.0052)$ (Figure $4(\mathrm{~d}))$. All values are listed in Table 3.

\section{Discussion}

To date, most experimental and clinical tissue engineering trials in craniofacial surgery have used BM-derived stromal cells from the iliac crest $[24,25]$. In a previous work we demonstrated that cells isolated from mandibular and maxillary bone, periosteum from the oblique line, and dental pulp exhibit the characteristics of cells described as MSPCs [7]. For the first time, the role of mechanical stimulation in osteogenic differentiated intraoral MSPCs is the subject of investigation. Consequently, explant cultures of human MSPCs have been established from human intraoral tissue samples of posterior maxilla and mandibular retromolar bone and characterized as MSPCs according to the criteria of the International Society for Cellular Therapy [26] using flow cytometry analysis. The low number of CD45-positive cells 

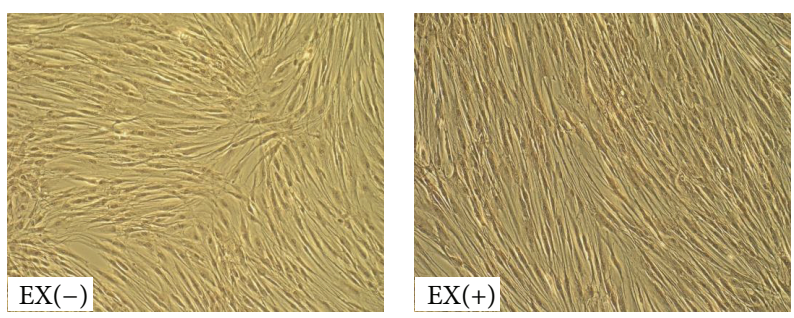
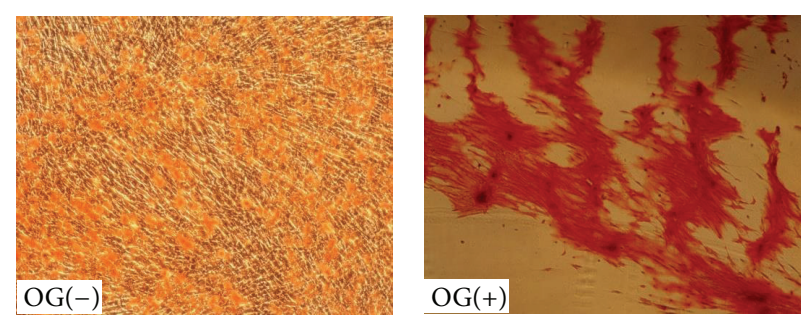

(a)

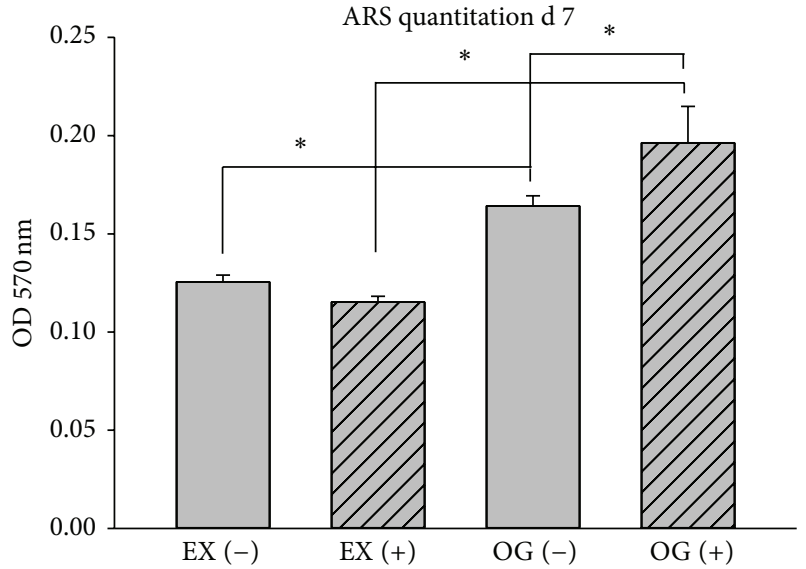

(b)

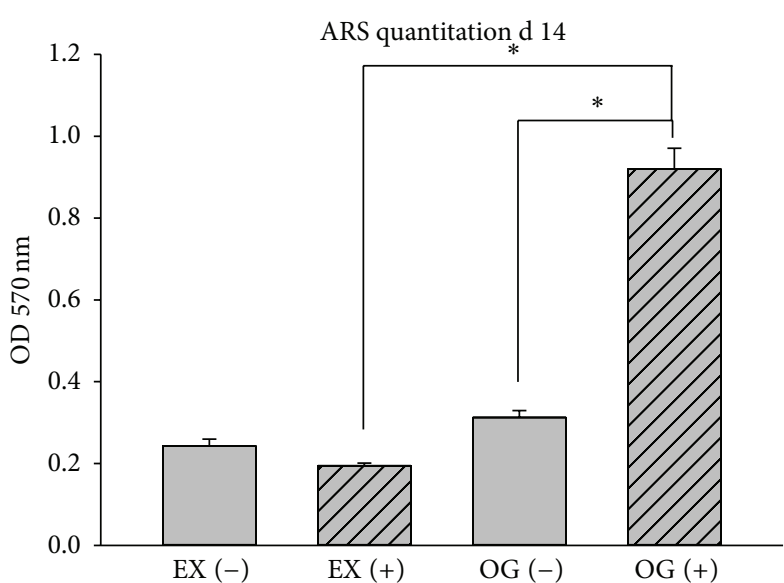

(c)

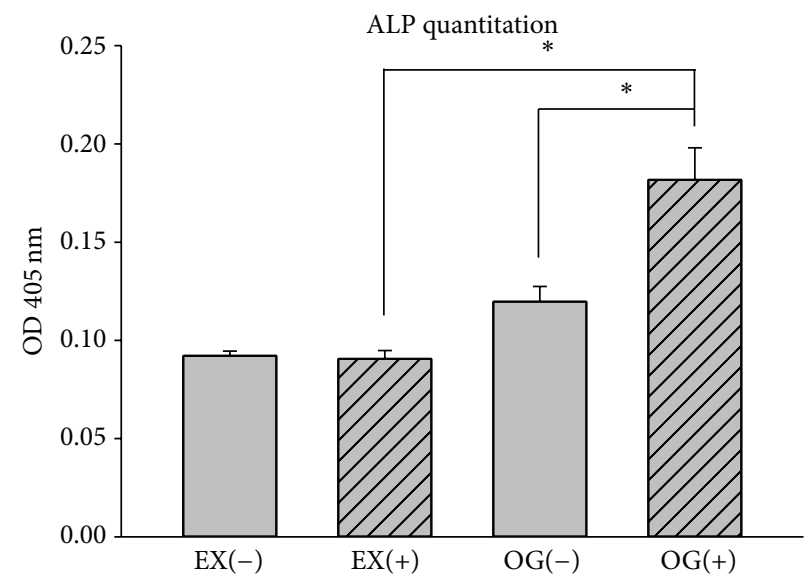

(d)

FIGURE 4: Influence of mechanical stimulation on alkaline phosphatase (ALP) expression and demonstration of mineralized matrix using ARS staining of human intraoral MSPCs. (a) Representative pictures of unstained $(\mathrm{EX}(-)$ and $\mathrm{EX}(+))$ and osteogenic differentiated $(\mathrm{OG}(-)$ and $\mathrm{OG}(+))$ MSPCs. Quantitation of calcium deposited into the cultures revealed a significant increase in the $570 \mathrm{~nm}$ OD in osteogenic differentiated and mechanically stimulated MSPCs after (b) 7 days and (c) 14 days, when compared to undifferentiated controls. (d) Quantitation of ALP enzymes revealed a significant increase compared to corresponding controls. EX(-) represents the undifferentiated mechanically unstimulated group, $\mathrm{EX}(+)$ the undifferentiated mechanically stimulated group, OG(-) the osteogenic differentiated mechanically unstimulated group, and $\mathrm{OG}(+)$ the osteogenic differentiated mechanically stimulated group. The values are mean \pm SD of independent experiments performed in triplicate $(n=9) ;{ }^{*} P<0.05$.

indicates that the bone-derived cultures contain immature mesenchymal cells. The small number of CD45-positive cells was reported in the surface profile of adult MSPCs [27]. Yu et al. demonstrated these small CD45-positive subpopulations in adipose tissue-derived MSPCs as well [28].
In vitro, bone cells demonstrate a high responsiveness to mechanical stimuli. Much debate exists regarding the critical components of the load profile and whether different components, such as fluid shear, tension, or compression, influence cells differently. The most widely used mechanical stimuli 
in vitro are cyclic stretch and fluid shear flow [29]. We seeded the intraoral MSPCs onto collagen type-I-coated BioFlex plates and stimulated them mechanically using a continuous uniaxial sinusoidal waveform with $10 \%$ elongation and a frequency of $0.5 \mathrm{~Hz}$.

$\mathrm{LDH}$ release and the expression of osteogenesis-specific markers were analysed after 7 and 14 days. The effect of mechanical loading on the proliferation of osteoblastic cells is controversial. Some studies have shown that an appropriate amount of mechanical force can induce the growth of BMMSPCs [30], while others have found the opposite [31]. In our experiments, the relative levels of $\mathrm{LDH}$ in the $0 \%$ and $10 \%$ strained groups showed no significant changes. These findings suggest that $10 \%$ cyclic strain did not change the survival rate of intraoral MSPCs or induce serious cellular damage.

Similar to the results on rat BM-MSPCs reported by Zhao et al. [32], our RT-qPCR data showed significantly increased mRNA expression levels of type-I collagen (CollA1), osteonectin (SPARC), bone morphogenetic protein 2 (BMP2), alkaline phosphatase (ALPL), osteopontin (SPP1), and osteocalcin (BGLAP) in the mechanically stimulated groups. The runt-related transcription factor 2 (RUNX2) is considered to be the central control gene within the osteoblast phenotype. Xiao et al. have shown that levels of RUNX2 during in vitro differentiation of primary human osteoblasts showed no major changes, whereas levels of downstream genes such as bone sialoprotein and alkaline phosphatase were dramatically increased [32, 33]. Furthermore, real-time PCR and western blot analyses indicated that there was no significant increase in the amount of RUNX2 protein or mRNA during human osteoblast differentiation [34].

However, although the expression level of RUNX2 showed no significant differences in human intraoral MSPCs, our RT-qPCR data showed significantly increased mRNA expression levels of the RUNX2 downstream genes CollA1, ALPL, SPP1, and BGLAP in the mechanically stimulated groups. The most prominent difference we observed between unstimulated and mechanically stimulated, osteogenic differentiated MSCPs was in the expression of BMP2. This result is similar to the findings of Sumanasinghe et al., who demonstrated that BMP2 mRNA is significantly increased in strained groups [16]. The late stage markers SPP1 and BGLAP play an important role in the differentiation of osteoblast progenitor cells, with significant upregulation observed in both matrix synthesis and mineralisation. Our results are in accordance with other studies, which demonstrated an upregulation of these genes with steady increases as osteoblastic differentiation progresses $[34,35]$. Both ALP activity and the production of mineralized matrix were significantly upregulated by mechanical stimulation in our human intraoral MSPCs. The production of mineralised matrix is considered a marker for terminally differentiated MSPCs into osteoblastlike cells [36]. Therefore, mineral formation is an appropriate indicator underpinning the fact that mechanical stimulation accelerates the osteogenic differentiation of MSPCs. The protein levels have also been shown to be upregulated in response to the application of mechanical force [34].

\section{Conclusion}

Our results revealed that $10 \%$ cyclic strain induced a significant increase in the mRNA expression of the osteogenesis-specific markers in osteogenic differentiated intraoral MSPCs. The increasing evidence for mechanical stimulation as a regulator of osteogenic differentiation in MSPCs holds important consequences for the development of craniofacial surgery and orthopaedic tissue engineering solutions. Further, molecular mechanisms underlying cellular responses to mechanical stimulation are not well understood. Thus, further investigation is necessary to better understand the molecular mechanism underlying the effects of mechanical stimulation on the osteogenic differentiation of human intraoral MSPCs.

\section{Conflict of Interests}

The authors declare that there is no conflict of interests regarding the publication of this paper.

\section{Acknowledgments}

The authors would like to thank Jennifer Ober for excellent technical assistance with flow cytometric analysis and Dr. Katharina Schallmoser, Department of Blood Group Serology and Transfusion Medicine, Medical University of Graz, for providing the pHPL. Financial support by the Medical University of Graz is gratefully acknowledged.

\section{References}

[1] R. Quarto, M. Mastrogiacomo, R. Cancedda et al., "Repair of large bone defects with the use of autologous bone marrow stromal cells," The New England Journal of Medicine, vol. 344, no. 5, pp. 385-386, 2001.

[2] E. Kon, G. Filardo, A. Roffi et al., "Bone regeneration with mesenchymal stem cells," Clinical Cases in Mineral and Bone Metabolism, vol. 9, no. 1, pp. 24-27, 2012.

[3] P. J. Marie, "Cell and gene therapy for bone repair," Osteoporosis International, vol. 22, no. 6, pp. 2023-2026, 2011.

[4] C. Clausen, N. U. Hermund, O. Donatsky, and H. Nielsen, "Characterization of human bone cells derived from the maxillary alveolar ridge," Clinical Oral Implants Research, vol. 17, no. 5, pp. 533-540, 2006.

[5] E. M. Horwitz, D. J. Prockop, L. A. Fitzpatrick et al., "Transplantability and therapeutic effects of bone marrow-derived mesenchymal cells in children with osteogenesis imperfecta," Nature Medicine, vol. 5, no. 3, pp. 309-313, 1999.

[6] E. M. Horwitz, P. L. Gordon, W. K. K. Koo et al., "Isolated allogeneic bone marrow-derived mesenchymal cells engraft and stimulate growth in children with osteogenesis imperfecta: implications for cell therapy of bone," Proceedings of the National Academy of Sciences of the United States of America, vol. 99, no. 13, pp. 8932-8937, 2002.

[7] B. Lohberger, M. Payer, B. Rinner et al., "Tri-lineage potential of intraoral tissue-derived mesenchymal stromal cells," Journal of Cranio-Maxillofacial Surgery, vol. 41, no. 2, pp. 110-118, 2013. 
[8] P. J. Boyne and R. A. James, "Grafting of the maxillary sinus floor with autogenous marrow and bone," Journal of Oral Surgery, vol. 38, no. 8, pp. 613-616, 1980.

[9] N. Jakse, F.-J. Seibert, M. Lorenzoni, A. Eskici, and C. Pertl, "A modified technique of harvesting tibial cancellous bone and its use for sinus grafting," Clinical Oral Implants Research, vol. 12, no. 5, pp. 488-494, 2001.

[10] C. Y. Lee, "Immediate load protocol for anterior maxilla with cortical bone from mandibular ramus," Implant Dentistry, vol. 15, no. 2, pp. 153-159, 2006.

[11] U. Meyer, H. P. Wiesmann, B. Kruse-Lösler, J. Handschel, U. Stratmann, and U. Joos, "Strain-related bone remodeling in distraction osteogenesis of the mandible," Plastic and Reconstructive Surgery, vol. 103, no. 3, pp. 800-807, 1999.

[12] E. G. Loboa, T. D. Fang, S. M. Warren et al., "Mechanobiology of mandibular distraction osteogenesis: experimental analyses with a rat model," Bone, vol. 34, no. 2, pp. 336-343, 2004.

[13] N. A. Waanders, M. Richards, H. Steen, J. L. Kuhn, S. A. Goldstein, and J. A. Goulet, "Evaluation of the mechanical environment during distraction osteogenesis," Clinical Orthopaedics and Related Research, no. 349, pp. 225-234, 1998.

[14] E. A. Smith-Adaline, S. K. Volkman, M. A. Ignelzi Jr., J. Slade, S. Platte, and S. A. Goldstein, "Mechanical environment alters tissue formation patterns during fracture repair," Journal of Orthopaedic Research, vol. 22, no. 5, pp. 1079-1085, 2004.

[15] G. Friedl, H. Schmidt, I. Rehak, G. Kostner, K. Schauenstein, and R. Windhager, "Undifferentiated human mesenchymal stem cells (hMSCs) are highly sensitive to mechanical strain: transcriptionally controlled early osteo-chondrogenic response in vitro," Osteoarthritis and Cartilage, vol. 15, no. 11, pp. 12931300, 2007.

[16] R. D. Sumanasinghe, S. H. Bernacki, and E. G. Loboa, "Osteogenic differentiation of human mesenchymal stem cells in collagen matrices: effect of uniaxial cyclic tensile strain on bone morphogenetic protein (BMP-2) mRNA expression," Tissue Engineering, vol. 12, no. 12, pp. 3459-3465, 2006.

[17] A. Peters, D. Toben, J. Lienau et al., "Locally applied osteogenic predifferentiated progenitor cells are more effective than undifferentiated mesenchymal stem cells in the treatment of delayed bone healing," Tissue Engineering A, vol. 15, no. 10, pp. 29472954, 2009.

[18] K. Schallmoser, C. Bartmann, E. Rohde et al., "Human platelet lysate can replace fetal bovine serum for clinical-scale expansion of functional mesenchymal stromal cells," Transfusion, vol. 47, no. 8, pp. 1436-1446, 2007.

[19] C. Bartmann, E. Rohde, K. Schallmoser et al., "Two steps to functional mesenchymal stromal cells for clinical application," Transfusion, vol. 47, no. 8, pp. 1426-1435, 2007.

[20] A. Sabokbar, P. J. Millett, B. Myer, and N. Rushton, "A rapid, quantitative assay for measuring alkaline phosphatase activity in osteoblastic cells in vitro," Bone and Mineral, vol. 27, no. 1, pp. 57-67, 1994.

[21] C. A. Gregory, W. G. Gunn, A. Peister, and D. J. Prockop, "An Alizarin red-based assay of mineralization by adherent cells in culture: comparison with cetylpyridinium chloride extraction," Analytical Biochemistry, vol. 329, no. 1, pp. 77-84, 2004.

[22] S. A. Bustin, V. Benes, J. A. Garson et al., "The MIQE guidelines: minimum information for publication of quantitative real-time PCR experiments," Clinical Chemistry, vol. 55, no. 4, pp. 611-622, 2009.

[23] J. Vandesompele, K. de Preter, F. Pattyn et al., "Accurate normalization of real-time quantitative RT-PCR data by geometric averaging of multiple internal control genes," Genome Biology, vol. 3, no. 7, 2002.

[24] M. F. Pittenger, A. M. Mackay, S. C. Beck et al., "Multilineage potential of adult human mesenchymal stem cells," Science, vol. 284, no. 5411, pp. 143-147, 1999.

[25] E. Kon, A. Muraglia, A. Corsi et al., "Autologous bone marrow stromal cells loaded onto porous hydroxyapatite ceramic accelerate bone repair in critical-size defects of sheep long bones," Journal of Biomedical Materials Research, vol. 49, no. 3, pp. 328337, 2000.

[26] M. Dominici, K. Le Blanc, I. Mueller et al., "Minimal criteria for defining multipotent mesenchymal stromal cells. The International Society for Cellular Therapy position statement," Cytotherapy, vol. 8, no. 4, pp. 315-317, 2006.

[27] R. Mafi, S. Hindocha, P. Mafi, M. Griffin, and W. S. Khan, "Sources of adult mesenchymal stem cells applicable for muscoskeletal applications-a systematic review of the literature," Open Orthopaedics Journal, vol. 2, pp. 242-248, 2011.

[28] G. Yu, X. Wu, M. A. Dietrich et al., "Yield and characterization of subcutaneous human adipose-derived stem cells by flow cytometric and adipogenic mRNA analyzes," Cytotherapy, vol. 12, no. 4, pp. 538-546, 2010.

[29] M. Mullender, A. J. El Haj, Y. Yang, M. A. van Duin, E. H. Burger, and J. Klein-Nulend, "Mechanotransduction of bone cells in vitro: mechanobiology of bone tissue," Medical and Biological Engineering and Computing, vol. 42, no. 1, pp. 14-21, 2004.

[30] M. Jagodzinski, A. Breitbart, M. Wehmeier et al., "Influence of perfusion and cyclic compression on proliferation and differentiation of bone marrow stromal cells in 3-dimensional culture," Journal of Biomechanics, vol. 41, no. 9, pp. 1885-1891, 2008.

[31] G. Song, Y. Ju, X. Shen, Q. Luo, Y. Shi, and J. Qin, "Mechanical stretch promotes proliferation of rat bone marrow mesenchymal stem cells," Colloids and Surfaces B: Biointerfaces, vol. 58, no. 2, pp. 271-277, 2007.

[32] H. Zhao, H. Zhou, X. Wang, J. Dong, Y. Yang, and X. Zhang, "Effect of mechanical strain on differentiation of mesenchymal stem cells into osteoblasts," Journal of Biomedical Engineering, vol. 26, no. 3, pp. 518-522, 2009.

[33] G. Xiao, D. Wang, M. D. Benson, G. Karsenty, and R. T. Franceschi, "Role of the $\alpha 2$-integrin in osteoblast-specific gene expression and activation of the Osf2 transcription factor," The Journal of Biological Chemistry, vol. 273, no. 49, pp. 3298832994, 1998.

[34] C. Shui, T. C. Spelsberg, B. L. Riggs, and S. Khosla, "Changes in Runx2/Cbfa1 expression and activity during osteoblastic differentiation of human bone marrow stromal cells," Journal of Bone and Mineral Research, vol. 18, no. 2, pp. 213-221, 2003.

[35] M. Jagodzinski, M. Drescher, J. Zeichen et al., "Effects of cyclic longitudinal mechanical strain and dexamethasone on osteogenic differentiation of human bone marrow stromal cells," European Cells and Materials, vol. 7, pp. 35-41, 2004.

[36] G. N. Bancroft, V. I. Sikavitsas, J. van den Dolder et al., "Fluid flow increases mineralized matrix deposition in 3D perfusion culture of marrow stromal osteoblasts in a dose-dependent manner," Proceedings of the National Academy of Sciences of the United States of America, vol. 99, no. 20, pp. 12600-12605, 2002. 


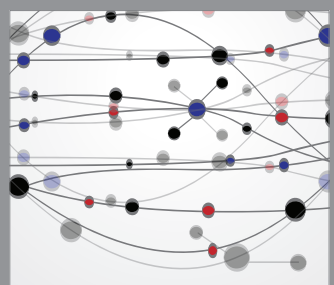

The Scientific World Journal
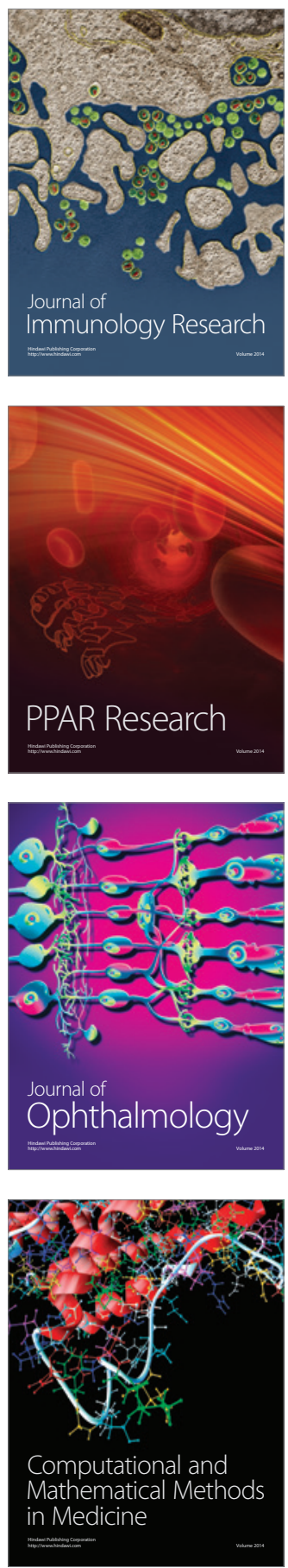

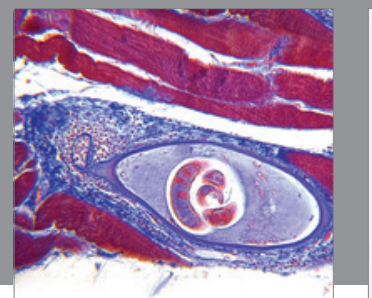

Gastroenterology

Research and Practice
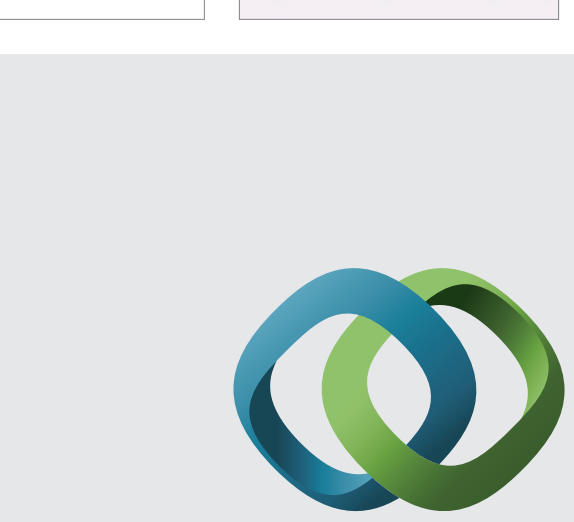

\section{Hindawi}

Submit your manuscripts at

http://www.hindawi.com
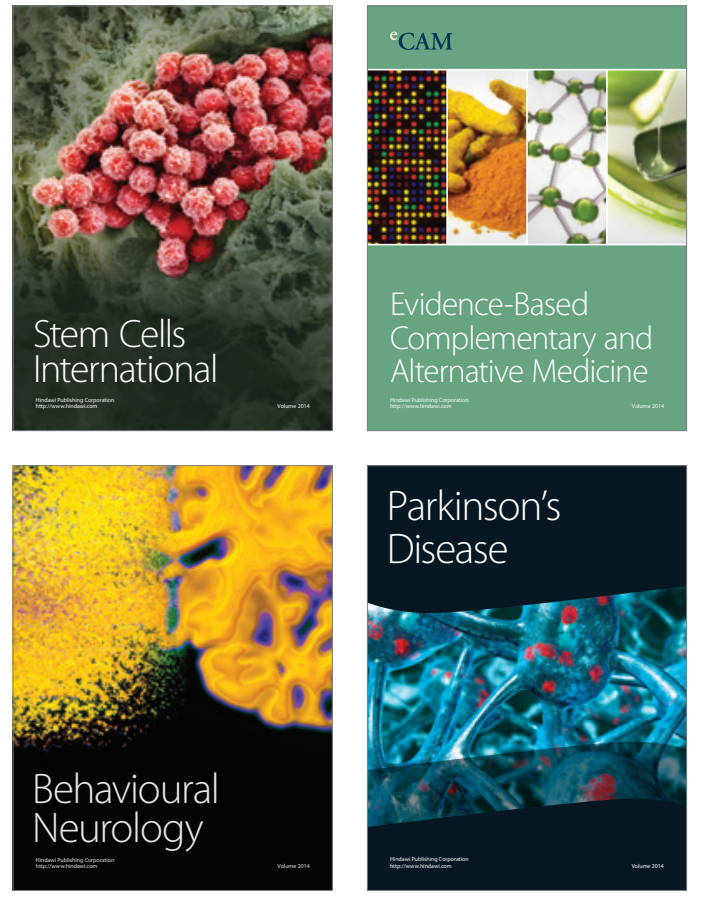
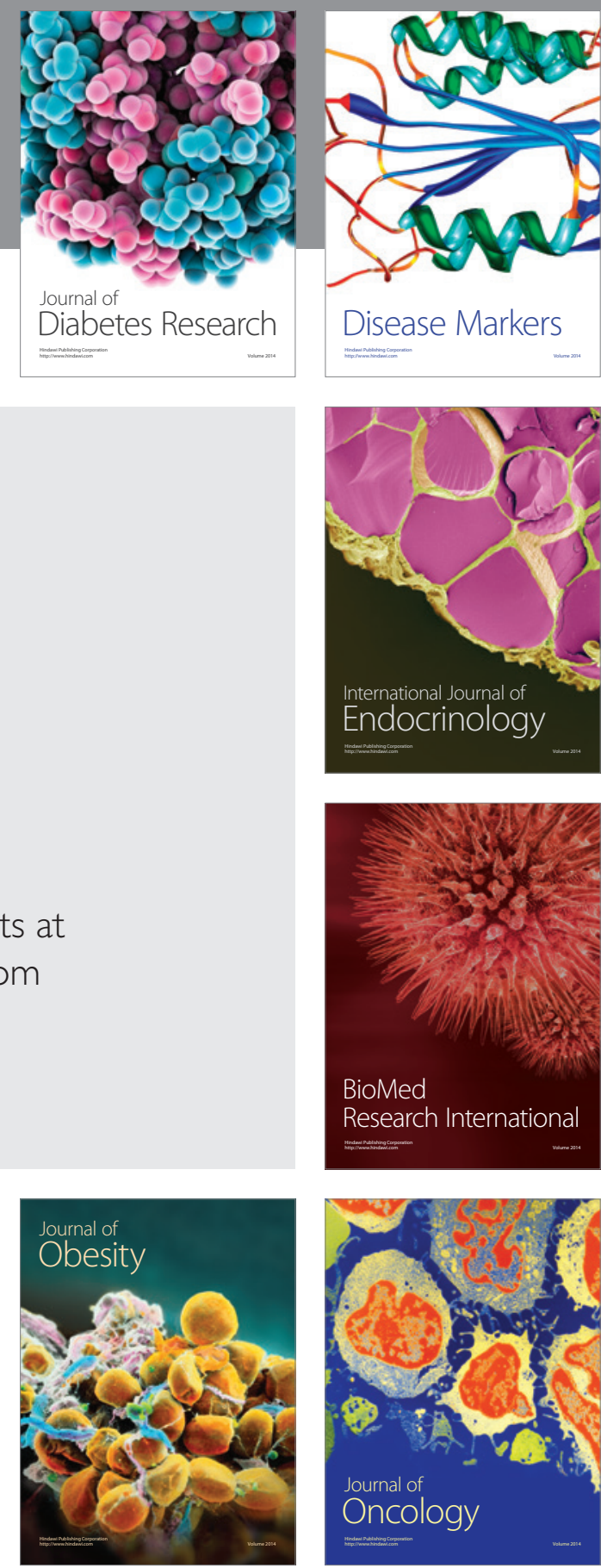

Disease Markers
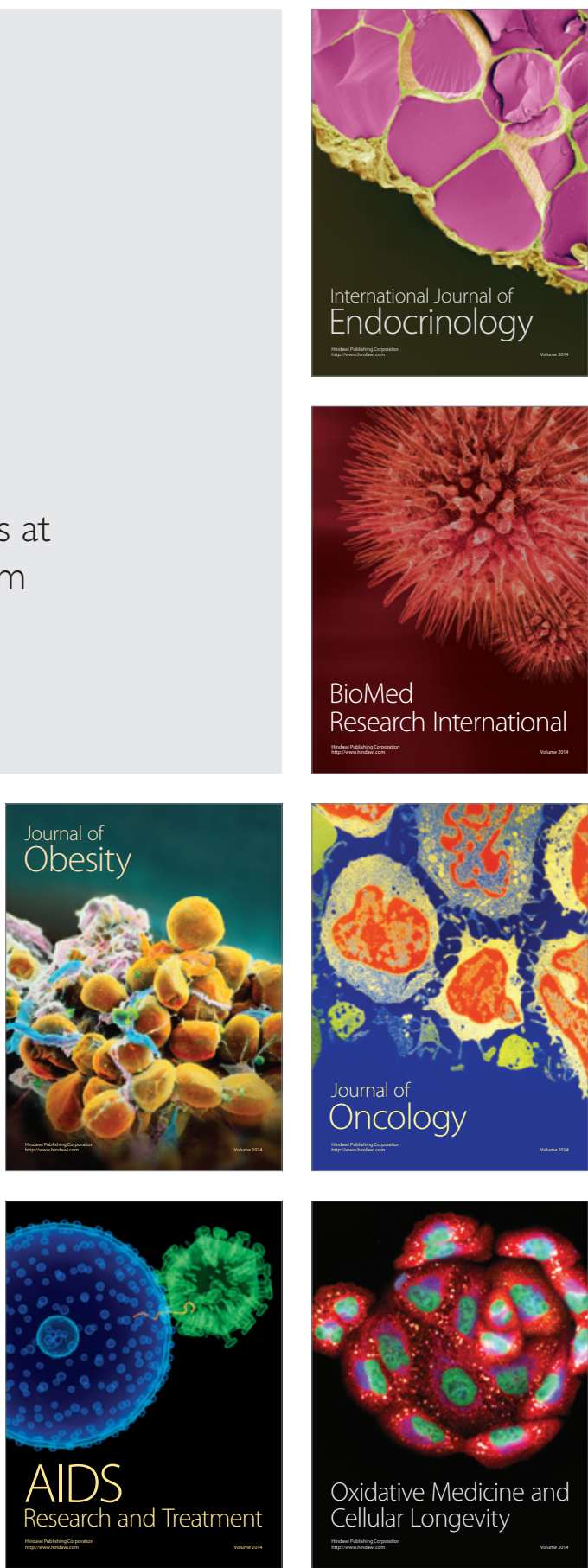